\title{
Practical Research on Constructing College Basketball Curriculum with the Concept of Health First
}

\author{
Shuang Liu \\ Beijing International Studies University, Beijing 100024, China \\ Email: 20140039@bisu.edu.cn
}

\begin{abstract}
In light of school sports in our country, physical education in colleges and universities is the last stage of school sports, which is an important means to implement quality education for college students and cultivate their comprehensive quality. Under the background of the profound reform of the current teaching concept of colleges and universities, college basketball curriculum is constantly undergoing innovation in concept and practice. To break the traditional teaching mode. To guide the reform in college basketball curriculum with the concept of health first and to construct a basketball curriculum mode conducive to the overall development of students' physical and mental health is the objective requirement of breaking through the bottleneck of college basketball curriculum teaching and comprehensively improving students' comprehensive quality.

Keywords: concept of health first, college basketball curriculum, basketball teaching
\end{abstract}

Basketball is one of the most popular sports among college students and an important part of physical education in colleges and universities. In college physical education, basketball education has also received extensive attention from the leaders of education departments and the school. Almost all colleges and universities put basketball course into teaching plan as the basic content of physical education. However, through the investigation and study, it is discovered that nowadays many college students has showcased no interest in the school's basketball class, which is commonly seen among students majoring sports. They generally think basketball class is not as good as competition, and even some college students, as a true basketball enthusiast, also has no interest in basketball class. In the college basketball course, the students sit the basketball class with great expectation and curiosity, aiming to contact and understand basketball. Consequently, they are showed disappointment and reluctance in taking basketball course in colleges and universities, which greatly dampened the students' enthusiasm and initiative for taking basketball class. It has been a concern for us, worrying about its impact on students' interest in sports and reduced enthusiasm. The fundamental reason for the above phenomenon of basketball course in colleges and universities lies in the shackles of traditional basketball teaching ideas. Therefore, we think that to break the current college basketball course bottleneck is the fundamental path to construct the new teaching idea, in the teaching ideas of "Health First" as the basic construction of new college basketball course mode, stimulate students' learning initiative and enthusiasm, let the students in the process of actively participating in the all-round development of the physical and mental health were obtained through the basketball course progress.

\section{Main problems in college basketball courses under the concept of health first}

\subsection{Teachers are the overwhelming leader in curriculum teaching and implementation}

In the current basketball course in colleges and universities, despite the complete academic system, the existing basketball curriculum is still centered on certain teaching standards and implemented under the overwhelming leadership of teachers. Basically, the class is conducted based on routine basketball moves and techniques with the syllabus requirements as the center. This kind of course content and teaching mode dampened students' enthusiasm of learning basketball to varying degrees. In the era of implementation of credit system in colleges and universities, many students choose basketball courses just to get the corresponding credits in physical education to complete their studies. This kind of teacher-dominated basketball course mode makes basketball teaching become one-sided "indoctrination", showing no real significance of promoting students' physical and mental health development.

\subsection{Focus on professional skills with neglect of the development of physical and mental health}

At present, in the implementation of basketball courses in colleges and universities, almost all colleges and universities have established a set of assessment standards for reaching the standard, but this standard is almost based on the corresponding basketball professional movements and technical indicators. Students' physical and mental health indicators are hardly 
reflected in the evaluation standards and basketball curriculum content, organization and implementation. Basketball courses become a mere "course to vandalize muscles and bones" instead of "improving physical and mental health", which deviates from the essence of promoting physical and mental health as one of the sports.

\subsection{Few extracurricular basketball sports and poor physical exercise environment}

To achieve the promotion of students' physical and mental health development by basketball sports, it is far more enough to take in class basketball courses, rather, the corresponding extracurricular basketball sports activities are required to create the corresponding physical training environment so as to enable the students to develop the awareness of independent participation of basketball sports in superior physical exercise environment. However, the current basketball courses in colleges and universities are generally lingered at the level of classroom teaching. More badly, the practical courses are conducted with stiff instruction by teachers in some simple movements. As a consequence, the only physical education classroom teaching is also artificially seriously castrated, the actual effect failed to be given full play.

\subsection{More attaches on professional skills than spiritual qualities in teaching assessments}

In the current college basketball course evaluation standards, professional skills are almost taken as the evaluation elements. However, the teamwork spirit, sports participation, physical health, psychological health and social adaptation that students should have through basketball course learning are seldom reflected in the course learning evaluation and assessment. A few have introduced these evaluation indicators, but the weight is also low, physical education teachers mainly evaluate basketball professional sports skills as the standard.

\section{Causes of problems in college basketball courses under the health first concept}

According to the results of practical investigation and analysis, there are profound reasons for many problems that do not accord with the health first concept in the current college basketball curriculum. On the one hand, the traditional teaching concept is based on utilitarianism. Traditional college teaching philosophy tends to utilitarianism, that is, to cultivate students' practical professional skills in social employment, so that students can make a living with the knowledge and skills they have learned, which leads to the basketball course from the content, to teaching, and later teaching evaluation all highlight the training of basketball professional skills. On the other hand, the current college basketball teaching traditional concept is gradually broken, but the new concept is not really established, resulting in college basketball curriculum is in the transition period of reform and innovation, failed to form a unified, scientific teaching concept and model, resulting in the basketball curriculum is still in a state of confusion. Finally, the teaching concept is not really implemented in practice. Teaching concept or theory is difficult for implementation in practice, which is a problem in the course teaching in colleges and universities. It is subject to a series of subjective and objective factors to a great extent. Universities and colleges witnessed long duration in implementation of teaching ideas and theories with difficulty in basketball teaching, which is a common problem. Although our country has issued a series of college PE teaching guidance, as a matter of fact, these requirements are very difficult to be truly implemented in a comprehensive and effective manner.

\section{Innovative path of college basketball curriculum under the guidance of health first concept}

\subsection{Innovating the curriculum implementation concept and implement the curriculum concept of health first}

The curriculum concept is an important guide for the implementation of basketball curriculum. The current basketball curriculum concept in colleges and universities is mainly based on the traditional curriculum concept, and almost carries out simple basketball skills and tactics training teaching according to the teaching syllabus. The development of students' physical and mental health has not really become the basic guiding concept for the implementation of basketball curriculum. Concept of curriculum implementation, therefore, we believe that innovation curriculum implementation should be conducted based on the basic idea of students' health. The curriculum content, curriculum construction, teaching evaluation, evaluation of student performance should be in accordance with the requirements of the students' physical and mental development for comprehensive improvement, so that health first concept will run through each stage in teaching. In the course practice, the promotion effect of basketball course on students' physical and mental health is comprehensively improved.

\subsection{Improving of the evaluation method of basketball course based on the health first concept}

On the basis of fully reflecting the concept of students' physical and mental health development, we should reform 
and innovate the assessment and evaluation mechanism, and comprehensively promote the promotion effect of curriculum implementation on students' health by using assessment and evaluation. The guiding ideology of assessment and evaluation should meet the requirements of "Outline of Teaching Guidance for PE Courses in National Colleges and Universities". According to the basketball course objectives, students' course learning should be comprehensively evaluated and assessed. In terms of assessment content and standards, students' grasp of basic basketball skills should be highlighted. At the same time, we should pay attention to students' learning attitude, teamwork, communication and other non-intellectual factors based on basketball teaching in the course. In the practice process of assessment and evaluation of students, attention should be given to individual students, the development and progress of individual students should be included in the assessment content on the basis of highlighting individual differences, and the selection and screening function of assessment and evaluation should be diluted. The students' physical and mental health and physical education professional skills, on the basis of the organic combination of evaluation on teaching evaluation to promote the comprehensive development of students' physical and mental health survey initiative of students to participate in the activities of basketball teaching and enthusiasm, improve students self-exercise and consciousness, help students form good sports habit of lifelong exercise.

\subsection{Transforming of the traditional mode of teachers in dominant position to top priority on students}

It is necessary to change the situation of teacher's dominance in curriculum teaching from the perspective of studentoriented and highlighting the student-subject status. Teachers should change the current one-way indoctrination, single teaching method, improve and optimize teaching methods. Accordingly, we should highlight the dominant position of students in teaching activities. In light of the innovation in the study and basketball teaching methods, the active exploration of the teaching model can effectively stimulate students interest in learning, cultivate students' innovative thinking, especially in the basketball movement based adjustments ability. Besides, the heuristic, discussion-based teaching method should be fully utilized in teaching with attention to classroom teaching so as to give students enough free time for independent learning and thinking, which will serve as a guide for students to participate in the whole process of teaching. As a result, students will show willingness in thinking with doubts in mind in the teaching process, and they will give them possible answers to the questions. While giving instructions on basketball skills to students, attentions should be paid to teaching basketball referee rules, basketball tournament organization and management methods so as to make full use of teaching and training games to cultivate basketball based team spirit and awareness, as a result, to develop self-protection awareness. In addition, teachers also need to make full use of multimedia teaching to play classic games video for introduction of basketball theoretical knowledge to students in teaching. Therefore, basketball skills and related tactical knowledge can be introduced in a comprehensive manner.

\subsection{Carrying out basketball activities outside school and creating a good sports training environment}

Earnestly implementing the physical health standard " and to have in-depth study and understand the national ordinary university sports curriculum teaching instruction summary "proposed" to have a purpose, planned and organized extracurricular physical exercise and training program into the physical education curriculum, such as inside and outside of the form class organic face-to-face contact the course structure of "break the basketball course only the old mode of classroom teaching, Pay attention to the comprehensive development of basketball sports activities in and out of class and school, so that college students outside the basketball sports activities on the system of protection. The life concept of "one hour exercise per day for 50 years of healthy work and a happy life for a lifetime" will be deeply rooted in every student's heart. For the extracurricular teaching, the extracurricular basketball activities should be actively organized and guided, for example, basketball fraternity games among classes, departments and colleges and universities can be held for at the weekend. Basic skills competition and the school basketball team and the basketball game between social organizations, authorities can be held to raise the level of college basketball. To hold special lectures on basketball and basketball appreciation will enrich the basketball based cultural atmosphere on campus and stimulate students' interest in basketball, as a result, their sports awareness can be enhanced, which will lay a solid foundation for lifelong sports for college students. In addition, colleges and universities can strengthen the investment in basketball facilities, basketball venues, construction of stadiums and gymnasiums to advance the opening time for college students to create a good environment for sports.

\subsection{Improving of the quality of basketball teachers and cultivating high-quality comprehensive teachers}

Paying attention to the improvement of teachers' comprehensive quality with focus on increasing investment so as to build a comprehensive basketball teaching team. It is imperative that teachers should change themselves from the traditional 
technical teachers to the comprehensive teachers with "theory + technology", and a professional contingent of teachers who are proficient in teaching basketball courses in colleges and universities should be developed. Teachers' professional skills and profound theoretical knowledge can be given full play to improve the teaching level of basketball course.

\section{Conclusion}

College basketball course teaching is a curriculum problem involving the training of basketball skills and sports spirit quality of students. Under the existing teaching concept, students' basketball skills training is highlighted, and students' spiritual quality, physical and mental health is not give enough attention, resulting in many problems, which runs counter to the goal of talent training in Lide Shuren. It is a basic trend and an important way for colleges and universities to carry out the task of cultivating moral talents and promoting the reform of basketball curriculum by comprehensively reforming and innovating college basketball curriculum and paying attention to the development of students' physical and mental health while cultivating students' basketball technical and tactical ability under the guidance of the concept of health first.

\section{References}

[1] Ministry of Education. Outline of teaching guidance for PE courses in national colleges and universities[S]. 2002.8.

[2] Li Zonghua. Research on Student Subjectivity based Teaching reform of basketball course in higher vocational colleges[J]. Journal of Changsha University of Physical Education, 2014.

[3] Zhao Haiyan. Discussion on the application of goal teaching method in college basketball Course [J]. Journal of Dalian Institute of Physical Education. 2013.

[4] Ma Qiwei. Sports Psychology [M]. Beijing: Higher Education Press. 2004: 53. 